\title{
Yersinia frederiksenii
}

National Cancer Institute

\section{Source}

National Cancer Institute. Yersinia frederiksenii. NCI Thesaurus. Code C86856.

A species of facultatively anaerobic, Gram negative, rod shaped bacteria in the phylum Proteobacteria. This species is motile, positive for urease, indole, ornithine decarboxylase, and pyrazinamidase and negative for oxidase. It is able to ferment sucrose, cellobiose, sorbitol, rhamnose, sorbose, inositol, and fucose but not raffinose, or melibiose. Y. frederiksenii is found in aqueous environments and may be an opportunistic pathogen. 